\title{
Consolidation of Extinction Learning Involves Transfer from NMDA-Independent to NMDA-Dependent Memory
}

\author{
Edwin Santini, ${ }^{1}$ Robert U. Muller, ${ }^{2}$ and Gregory J. Quirk ${ }^{1}$ \\ ${ }^{1}$ Department of Physiology, Ponce School of Medicine, Ponce, Puerto Rico, 00732, and 2Department of Physiology, \\ State University of New York Health Science Center at Brooklyn, Brooklyn, New York 11203
}

\begin{abstract}
Extinction of conditioned fear to a tone paired with foot shock is thought to involve the formation of new memory. In support of this, previous studies have shown that extinction of conditioned fear depends on NMDA receptor-mediated plasticity. To further investigate the role of NMDA receptors in extinction, we examined the effects of the NMDA antagonist $D(-)-3-(2-$ carboxypiperazine-4-yl)-propyl-1-phosphonic acid (CPP) on the extinction of conditioned freezing and suppression of bar pressing (conditioned emotional response). Rats extinguished normally during a 90 min session in the presence of systemic CPP (10 mg/kg), but were unable to recall extinction learning 24 hr later. This suggests that an NMDA-independent form of plasticity supports short-term extinction memory, but NMDA receptors are required for consolidation processes leading to long-term extinction memory. Surprisingly, extinction learned in the presence of CPP was recalled normally when tested $48 \mathrm{hr}$
\end{abstract}

after training, suggesting a delayed consolidation process that was able to improve memory in the absence of further training. Delayed consolidation involves NMDA receptors because CPP injected on the rest day between training and test prevented 48 hr recall of extinction learned under CPP. Control experiments showed that the effect of CPP on memory consolidation was not caused by state-dependent learning or reduced expression of freezing under CPP. These findings demonstrate that NMDA receptor activation is critical for consolidation of extinction learning and that this process can be initiated after training has taken place. We suggest that consolidation of extinction involves off-line relearning that reinforces extinction memory through NMDA-mediated plasticity, perhaps in prefrontalamygdala circuits.

Key words: fear conditioning; medial prefrontal cortex; amygdala; spontaneous recovery; LTP; infralimbic
Pavlovian fear conditioning is an important animal model of emotional learning in which a neutral stimulus such as a tone is paired with an aversive stimulus such as a foot shock. After several such pairings, the tone comes to elicit stereotyped fear behaviors such as freezing, response suppression, and autonomic changes (Quirk et al., 1995; Killcross et al., 1997; Fendt and Fanselow, 1999; Gewirtz and Davis, 2000; LeDoux, 2000).

Repeated presentation of the now conditioned stimulus (CS) in the absence of the unconditioned stimulus (US) causes fear responses to extinguish. Pavlov (1927) observed that extinguished conditioned responses could spontaneously recover and that reconditioning occurred faster than initial conditioning, suggesting that extinction is not erasure of the CS-US association but is stored as a second form of memory. The notion that memory for extinction is distinct from memory for the initial fear conditioning is supported by a great deal of behavioral work (Rescorla and Heth, 1975; Bouton and Bolles, 1980; Bouton, 2000), but little is known about the neural circuits of extinction learning. Deficits in extinction of conditioned fear are seen after lesions of ventromedial prefrontal cortex (vmPFC) (Morgan et al., 1993; Quirk et al., 2000) (but see Gewirtz et al., 1997). In these animals, both freezing and response suppression decrease in a normal manner

\footnotetext{
Received June 11, 2001; revised Aug. 7, 2001; accepted Aug. 30, 2001.

This work was supported by National Institutes of Health Grants R29-MH58883 and S06-GM08239 to G.J.Q., and R01-NS20686, R01-NS37150, and a British Medical Research Council Grant to R.U.M. We thank James L. McGaugh for comments on an earlier version of this manuscript.

Correspondence should be addressed to Dr. Gregory J. Quirk, Department of Physiology, Ponce School of Medicine. P.O. Box 7004, Ponce, Puerto Rico 007327004. E-mail: gjquirk@yahoo.com.

Copyright (C) 2001 Society for Neuroscience $\quad 0270-6474 / 01 / 219009-09 \$ 15.00 / 0$
}

during a 90 min extinction session, but they return to much greater levels than in intact animals when tested $24 \mathrm{hr}$ later (Quirk et al., 2000). Thus, the same cortical lesions that markedly impair long-term memory do not impair short-term memory for extinction training.

Are short-term and long-term memory for extinction stored in the same way at the synaptic level? There is evidence that longterm extinction memory involves NMDA glutamate receptors. Infusion of the NMDA receptor antagonist 2-amino-5phosphonovalerate (APV) into the amygdala during extinction produced dose-dependent deficits in extinction carried out over several days (Falls et al., 1992; Lee and Kim, 1998), suggesting a long-term memory deficit. In addition, overexpression of NMDA receptor subunit NR2B in transgenic mice enhances extinction learning (Tang et al., 1999), presumably by increasing the size of NMDA-mediated calcium currents. However, little is known about the receptors involved in short-term extinction memory, and it is possible that short-term and long-term extinction memory are dissociable with pharmacological as well as anatomical methods.

In line with this possibility, it was recently shown that systemic injections of the NMDA antagonist $\mathrm{D}(-)$-3-(2-carboxypiperazine-4-yl)-propyl-1-phosphonic acid (CPP) did not interfere with the development of new positional firing patterns by hippocampal place cells in a novel environment (Kentros et al., 1998). Moreover, the new firing patterns were stable for $90 \mathrm{~min}$. In contrast, when the same cells were recorded in the novel environment $24 \mathrm{hr}$ later, the new firing patterns were abolished and replaced by a different set of patterns. Thus, NMDA receptors blocked by CPP are not necessary for the initial formation 
and short-term stability of place cell firing patterns but are required for long-term stability of those patterns.

We therefore asked whether systemic CPP given during extinction training would similarly spare short-term but impair longterm memory for extinction, in a manner similar to medial prefrontal cortex lesions. Systemic rather than intra-amygdalar injections of CPP were used to be able to rule out the possibility that NMDA receptors in other parts of the brain might be responsible for short-term extinction memory. We used a dose of CPP sufficient to block NMDA-dependant hippocampal longterm potentiation (LTP) (Abraham and Mason, 1988) and hippocampal primed-burst potentiation (Kentros et al., 1998).

A preliminary report of some of these data has been presented previously in abstract form (Quirk et al., 1999).

\section{MATERIALS AND METHODS}

Subjects. The procedures were approved by the Institutional Animal Care and Use Committee of the Ponce School of Medicine in compliance with National Institute of Health (NIH) guidelines for the care and use of laboratory animals (Publication DHHS NIH 86-23). The subjects were male Sprague Dawley rats weighing 270-300 gm. The animals were transported from the Ponce School of Medicine colony to a satellite facility where they were housed individually in transparent polyethylene cages inside a negative-pressure Biobubble (Colorado Clean Room, Ft. Collins, CO). Rats were maintained on a $12 \mathrm{hr}$ light/dark schedule with free access to water. Food was restricted to $10-15 \mathrm{gm}$ of standard laboratory rat chow per day until rats reached $85 \%$ of their original weight. During this $7 \mathrm{~d}$ period, rats were handled daily and acclimated to $45 \mathrm{mg}$ food pellets (Bioserve Inc., Frenchtown, NJ).

Bar-press training. Before fear conditioning, rats were trained to press for food on a variable interval schedule of reinforcement. Bar pressing produces a constant activity level against which conditioned freezing can be reliably measured during long sessions (Quirk et al., 2000). Pressing also allows for assessment of tone-induced suppression of spontaneous behavior, also known as the conditioned emotional response (see below). Bar-press training was performed in the fear conditioning chamber, and pellet delivery was controlled by the same computer program used to deliver tones and shocks (Winlinc, Coulourn Instruments, Allentown, PA). A continuous reinforcement schedule was gradually reduced to a variable interval schedule with reinforcement available every $60 \mathrm{sec}$ (VI-60). Eventually, rats learned to press at a rate of $\sim 20$ presses per minute. After bar-press training, rats were assigned to experimental groups using a pseudo-random number generator (http://www.randomizer.org).

Fear conditioning. Rats were fear conditioned and extinguished in the operant chamber while pressing for food. The chamber was $25 \times 29 \times 28$ $\mathrm{cm}$ with aluminum and Plexiglas walls (Coulbourn Instruments). The chamber floor was made from $0.5 \mathrm{~cm}$ stainless steel bars that could be electrified to deliver a mild shock. A response bar was positioned $6.5 \mathrm{~cm}$ above the floor, a speaker was mounted on the outside wall opposite the bar, and illumination was provided by a single overhead light. The chamber was situated inside a sound-attenuating box (Med Associates, Burlington, VT) that reduced ambient sound to $55 \mathrm{~dB}$ (caused by a ventilation system).

The CS was a $4 \mathrm{kHz}$ sine wave with a duration of $30 \mathrm{sec}$ and an intensity of $80 \mathrm{~dB}$ sound pressure level. The interval between successive tone presentations averaged $4 \mathrm{~min}$ (range, 2-6 min). The US was a 0.6 $\mathrm{mA}$ scrambled foot shock, $0.5 \mathrm{sec}$ in duration, that co-terminated with the tone. Rats were conditioned four at the same time in separate chambers.

Treatment groups and protocol. A total of 141 rats were used in four experiments. Each experiment had three experimental groups: (1) rats receiving saline injections plus extinction training (sal-ext group; $n=$ 50), (2) rats receiving CPP injections plus extinction training (CPP-ext group; $n=44)$, and (3) rats receiving saline injections but no extinction training (sal-no-ext group; $n=47$ ).

Experiment 1 took $3 \mathrm{~d}$. On day 1, all groups received five habituation trials (tone alone) followed by seven conditioning trials (tone paired with foot shock). After conditioning, rats were returned to their home cage for $1 \mathrm{hr}$ and then given an intraperitoneal injection of physiological saline or $10 \mathrm{mg} / \mathrm{kg}$ CPP, a competitive antagonist of NMDA receptors (Lehmann et al., 1987). After an additional $1 \mathrm{hr}$ delay to allow distribution of the drug $(2 \mathrm{hr}$ after conditioning), CPP-ext rats $(n=11)$ and sal-ext rats $(n=$ $15)$ were returned to the conditioning chamber and given 20 extinction trials (tone alone). Sal-no-ext rats $(n=13)$ were placed in the conditioning chamber for the duration of the extinction session but received no extinction tones. Twenty-four hours later (day 2), all groups were given 15 extinction trials to test for recall of extinction memory. An additional recall test was given on day 3 . Throughout conditioning and extinction, food was available ad libitum on a VI-60 schedule. Between days, the floor trays and shock bars were cleaned with soapy water, and the chamber walls were wiped with a damp cloth. Behavior was recorded with digital video cameras located inside the test chamber (Micro Video Products, Ontario, Canada). To permit scoring of freezing from videotape, an infrared light emitting diode, which was visible on tape but not to the rat, was illuminated during the tone.

In experiment 2 , there were $12 \mathrm{CPP}$-ext rats, 15 sal-ext rats, and 10 sal-no-ext rats. The procedure on day 1 was the same as in experiment 1 , including injection of CPP or saline before extinction training. On day 2, however, the rats remained in their home cage the entire day (a rest day). On day 3, 15 extinction trials were given to test for recall of extinction learning that took place $48 \mathrm{hr}$ earlier on day 1.

In experiment 3 , there were $9 \mathrm{CPP}$-ext rats, 8 sal-ext rats, and 12 sal-no-ext rats. The procedure was the same as in experiment 2 except that no injections were given on day 1 . Instead, rats were injected with CPP or saline on day 2 (the rest day). On day 3,15 extinction trials were given to test for recall of extinction learned $48 \mathrm{hr}$ previously.

In experiment 4 , there were 12 CPP-ext rats, 12 sal-ext rats, and 12 sal-no-ext rats. The procedure was similar to experiment 2 except that rats received injections both on day 1 and on day 2 (the rest day). Rats were then tested on day 3 for $48 \mathrm{hr}$ recall of extinction. In all experiments, all groups were drug-free at the time of test. In experiments 3 and 4 , rest day injections were given exactly $25 \mathrm{hr}$ after conditioning on day 1 .

Data analysis. We used two measures of conditioned fear: (1) percentage of time spent freezing (Blanchard and Blanchard, 1972) and (2) suppression of bar pressing for food (Estes and Skinner, 1941). Freezing is the cessation of all movements except respiration. The total time spent freezing during the $30 \mathrm{sec}$ tone was scored from videotape with a digital stopwatch by observers blinded with respect to experimental group. Bar presses were time stamped and stored on disk along with the tone onset. A suppression ratio was calculated from time-stamp data as follows: suppression ratio $=$ (pretone rate - tone rate) $/($ pretone rate + tone rate). This ratio normalizes for changes in baseline press rate (Bouton and Bolles, 1980). A value of +1 indicates complete suppression during the tone, whereas a value of 0 indicates no suppression.

Rats failing to acquire conditioned freezing (before injections) were excluded. To satisfy the criterion, a rat had to freeze $>0$ sec during either of the last two conditioning trials. This resulted in the exclusion of an equivalent number of rats in each group (sal-no-ext, 10\%; sal-ext, 14\%; CPP-ext, 15\%). The competition between freezing and motivation to press for food probably accounted for the failure to acquire conditioned fear in these animals.

Recall of extinction on the test day was expressed as the average freezing during trials 1-2 on the test day divided by the average freezing during conditioning trials 6-7. Termed "rebound," this measure assesses the extent of spontaneous recovery of extinguished responding (Quirk et al., 2000). Because of ceiling levels of conditioned suppression in some rats, only freezing was used to calculate rebound. Freezing and rebound values were analyzed with either Student's $t$ test or one-way ANOVA using repeated measures when appropriate (STATISTICA, Statsoft, Tulsa, OK). After a significant main effect, post hoc tests were performed with the Scheffé method.

\section{RESULTS}

\section{Experiment 1: extinction is learned under CPP but cannot be recalled $24 \mathrm{hr}$ later}

In Experiment 1 we tested the ability of rats to extinguish conditioned fear in the presence of CPP and to recall extinction learning $24 \mathrm{hr}$ later. Before drug injection, all experimental groups (sal-ext, CPP-ext, sal-no-ext) acquired equivalent amounts of conditioned freezing (Fig. 1A) and suppression responses to the tone CS. ANOVA revealed no main effect of treatment group for acquired freezing levels $\left(F_{(2,36)}=2.30 ; p=\right.$ 0.11). (Similarly, no group differences of acquired freezing level were seen in experiments 2, 3, and 4.) After conditioning, rats were injected with either CPP or physiological saline. CPP-ext 
A.

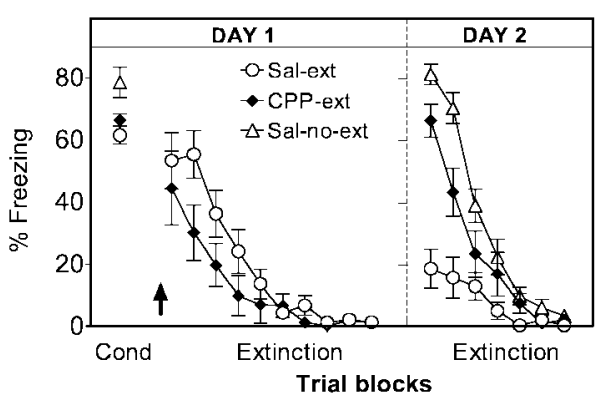

B

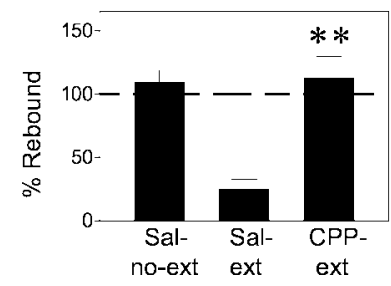

C.

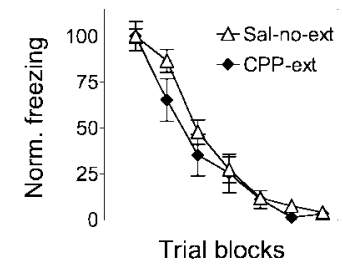

Figure 1. Experiment 1: CPP does not block extinction learning but prevents recall of extinction $24 \mathrm{hr}$ later. $A$, Average percentage freezing to the tone shown in blocks of two trials for no-extinction controls (Sal-noext, $\triangle ; n=13)$, CPP-extinction (CPP-ext, $\forall n=11)$, and salineextinction (Sal-ext, $\bigcirc ; n=15$ ) groups. The arrow indicates time of injection. Both sal-ext and CPP-ext groups extinguished their freezing responses on day 1 , but only sal-ext rats recalled extinction on day $2 . B$, Percentage rebound of freezing on day 2 for sal-no-ext, CPP-ext, and sal-ext groups. The CPP-ext group was significantly higher than the sal-ext group $(* * p<0.001)$ and not significantly different from sal-no-ext controls. $C$, Extinction of freezing on day 2 normalized to the first trial block. The rate of re-extinction was similar in both groups, suggesting no savings from extinction learned under CPP. In this and all subsequent figures, error bars indicate SEM.

and sal-ext groups were then given 20 trials of extinction training, whereas sal-no-ext rats received context exposure only.

$\mathrm{CPP}$ caused freezing levels to be somewhat reduced at the start of the extinction phase, although a Student's $t$ test comparing the first block of extinction trials was not statistically significant $(t=$ 0.59 ; $\mathrm{df}=24 ; p=0.56)$. Reduced freezing under NMDA blockade has been observed previously with APV injected into the amygdala (Maren et al., 1996; Lee and Kim, 1998; Fendt, 2001; Lee et al., 2001) and is consistent with a role of NMDA receptors in the expression of conditioned freezing. This apparent reduction in freezing was not accompanied by a general increase in activity because the rates of spontaneous bar pressing before and after injection of CPP did not differ $(t=-0.14$; $\mathrm{df}=10 ; p=0.45)$.

Despite a trend for reduced fear responses at the beginning of training, the extinction process in CPP-ext rats strongly resembled sal-ext rats. Both groups showed progressive decrements in freezing (Fig. 1A) and suppression as a function of extinction trials, ending with virtually no freezing and low suppression. Comparison of the first and last block of trials with repeatedmeasures ANOVA showed significant extinction of freezing in both CPP-ext and sal-ext groups (main effect of trials: $F_{(1,24)}=$ 44.23; $p<0.001$; post hoc tests: sal-ext, $p<0.001$; CPP-ext, $p<$ $0.01)$. Significant extinction of suppression was also observed (main effect: $F_{(1,24)}=33.91 ; p<0.001$; post hoc test: sal-ext, $p<$ 0.001; CPP-ext, $p<0.01$ ). In this and all subsequent experiments, the statistical conclusions for the suppression measure were identical to freezing, and for simplicity, only freezing will be reported.

On day 2, sal-ext rats showed little freezing and low suppres- sion, indicating good recall of extinction. In contrast, sal-no-ext rats showed high levels of freezing and suppression, reflecting both good recall of conditioning and the lack of extinction training. Crucially, the responses of the CPP-ext rats strongly resembled those of the sal-no-ext rats, showing high levels of conditioned responses despite complete extinction on the previous day, suggesting amnesia for the extinction process. To test impressions gained from inspection of freezing versus time curves, we calculated the percentage rebound of freezing on day 2 in all groups (Quirk et al., 2000). As expected, sal-ext rats rebounded very little (25\%), whereas CPP-ext rats rebounded to the full conditioned response acquired the day before $(112 \%)$ (Fig. $1 B$ ). In fact, CPP rats were not significantly different from no-extinction controls $(110 \% ; p=0.98)$, suggesting amnesia for extinction learning. One-way ANOVA of rebound values revealed a significant main effect of drug: $F_{(2,36)}=20.83 ; p<0.001$. Scheffé post hoc comparisons indicate that the CPP-ext group was significantly higher than the sal-ext group $(p<0.001)$ but not significantly different from sal-no-ext controls $(p=0.984)$. The apparent amnesia for extinction learning was also evidenced by the lack of savings in the rate of re-extinction on day 2. CPP-ext rats did not re-extinguish appreciably faster than the sal-no-ext rats, which were extinguished for the first time on day 2 (Fig. 1C). Thus, NMDA receptors do not appear to be necessary for short-term (within-session) extinction memory but are necessary for the formation of long-term extinction memory.

The high freezing observed in CPP animals on day 2 also indicates that CPP injected $1 \mathrm{hr}$ after conditioning does not interfere with recall of the conditioning memory. This is consistent with previous reports showing that NMDA blockers given immediately after fear conditioning did not affect recall of conditioning memory $24 \mathrm{hr}$ later (Kim et al., 1991; Maren et al., 1996).

Additional extinction trials on day 3 showed no significant freezing in any of the groups. Thus, when CPP-ext rats underwent a second extinction experience in the absence of CPP, they showed normal recall of extinction $24 \mathrm{hr}$ later.

\section{Experiment 2: extinction learned under CPP can be recalled $48 \mathrm{hr}$ later}

The results of experiment 1 suggest that rats are amnesic for extinction learned under CPP. If true, deficits in recall of extinction should be permanent. To test this prediction, we repeated experiment 1, except that recall was tested $48 \mathrm{hr}$ instead of $24 \mathrm{hr}$ after extinction learning. Thus, animals remained in their home cages throughout day 2 and were tested on day 3 .

On day 1 , the findings of the last experiment were replicated. At the start of the extinction phase, CPP-injected rats showed reduced expression of freezing that just reached significance $(t=$ 2.08; df $=25 ; p=0.048)$. Both CPP-ext and sal-ext rats extinguished completely over the course of the extinction training. When tested $48 \mathrm{hr}$ later, sal-ext rats showed good memory for extinction, whereas the sal-no-ext rats showed good memory for conditioning (Fig. 2A). To our surprise, however, the CPP-ext rats exhibited no more fear responses than the sal-ext rats, indicating normal recall of extinction rather than amnesia. The rebound measure (Fig. $2 B$ ) further indicated that both sal-ext and CPP-ext rats remembered the extinction experience, whereas sal-no-ext rats exhibited memory for the conditioning phase only. Rebound values were 31, 33, and 97\% for sal-ext, CPP-ext, and sal-no-ext, respectively. One-way ANOVA of rebound values revealed a significant main effect of group $\left(F_{(2,34)}=18.72 ; p<\right.$ 


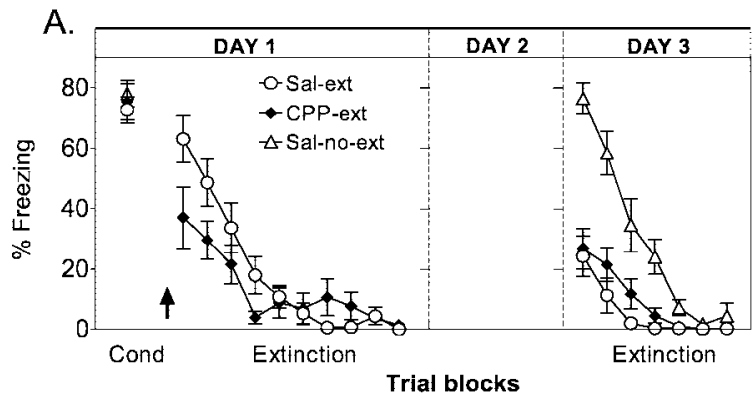

B.

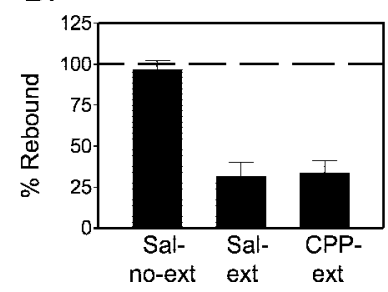

Figure 2. Experiment 2: recall of extinction is normal when tested $48 \mathrm{hr}$ after extinction under CPP. $A$, Average percentage freezing to the tone for sal-no-ext $(n=10)$, CPP-ext $(n=12)$, and sal-ext $(n=15)$ groups. Unlike experiment 1 , CPP-ext rats showed normal recall of extinction memory when tested after a $48 \mathrm{hr}$ delay. $B$, Percentage rebound of freezing on day 3 .

0.001). Post hoc comparisons indicated that CPP-ext rats were not significantly different from sal-ext rats $(p=0.98)$, and the sal-noext group was significantly higher than both the CPP-ext and sal-ext groups $(p<0.001)$. Thus, merely increasing the delay between extinction training and test reversed the amnesic effect of CPP observed in the previous experiment.

A key additional inference may be made from these findings. The apparent amnesia in experiment 1 could be attributable to a state-dependent effect (Overton, 1985) of CPP in which the drug acts as a discriminable stimulus that must be present at test to reproduce the conditions under which extinction took place. However, the lack of rebound on day 3 in the present experiment argues strongly against the state-dependent explanation, because rats were also drug-free at test, suggesting a true amnestic effect of CPP in experiment 1 .

\section{Experiment 3: CPP given only on the rest day has no effect}

Is the high rebound observed 24 but not $48 \mathrm{hr}$ after learning caused by a residual effect of CPP that exaggerates fear of tones in a time-dependent manner? If true, any extinction test performed $24 \mathrm{hr}$ after administration of CPP should show elevated freezing. We looked for this effect in experiment 3 by giving CPP on day 2 (the rest day) instead of day 1 and testing for recall of extinction on day 3 .

CPP-ext and sal-ext groups extinguished completely on day 1 , a drug-free day (Fig. 3). On day 3, sal-ext rats showed significant retention of extinction, rebounding to $60 \%$, whereas sal-no-ext rats rebounded to $123 \%$ as expected. CPP-rats also showed retention of extinction, rebounding to $40 \%$, indicating that the drug injection on day 2 did not interfere with recall of extinction learned in the absence of CPP. One-way ANOVA of rebound values showed a significant main effect of group $\left(F_{(2,26)}=15.06\right.$; $p<0.001)$. Post hoc comparisons confirmed that CPP-ext rats and sal-ext rats recovered similar levels of freezing $(p=0.26)$, but the sal-no-ext control showed higher rebound than both CPP-ext and
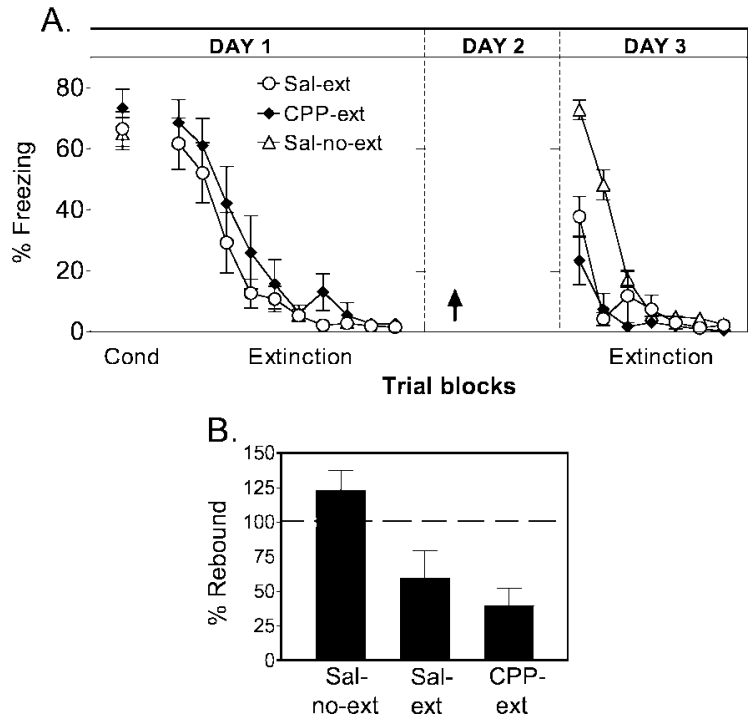

Figure 3. Experiment 3: CPP injected only on a rest day has no effect on recall of extinction $24 \mathrm{hr}$ later. $A$, Average percentage freezing to the tone for sal-no-ext $(n=12)$, CPP-ext $(n=9)$, and sal-ext groups $(n=8)$. Rats were injected in their home cages on the day between training and testing. CPP-ext rats showed normal recall of extinction memory on day 3 . $B$, Percentage rebound of freezing on day 3 .

sal-ext groups $(p<0.01)$. Thus, CPP injections that were not associated with extinction training had no effect on conditioned freezing $24 \mathrm{hr}$ later. Consistent with this, it has been shown that the effect of CPP on hippocampal primed-burst potentiation is completely worn off after $24 \mathrm{hr}$ (Kentros et al., 1998). Therefore, the results of experiment 1 cannot be attributed to residual effects of the drug $24 \mathrm{hr}$ after administration.

\section{Experiment 4: CPP given on the rest day blocks recall of extinction learned under CPP}

The results of experiments 1 and 2 showed that extinction memory, which was inaccessible on day 2 , became accessible on day 3 without further training. This suggests that some residual information was stored during extinction training under CPP, which resulted in a partial memory that was not accessible on day 2 . Presumably, a delayed consolidation process allowed this information to be modified during day 2 to yield a fully functional memory by day 3 . Given that initial consolidation of extinction memory up to the $24 \mathrm{hr}$ time point required NMDA receptors (experiment 1), would delayed consolidation also require NMDA receptors? We addressed this possibility in experiment 4 by injecting CPP on both days 1 and 2 and testing for recall on day 3. Thus, NMDA receptors were blocked during extinction training and during part of the rest day.

As in experiments 1 and 2, CPP reduced freezing at the start of the extinction session $(t=3.04$; df $=22 ; p<0.01)$ but did not prevent extinction (Fig. 4). On day 3, the groups responded almost identically to experiment 1 . Sal-no-ext and sal-ext groups showed retention of conditioning and extinction, respectively, whereas CPP-ext rats showed little evidence of extinction memory. Rebound values were $21 \%$ for sal-ext animals, $86 \%$ for CPP-ext animals, and $107 \%$ for sal-no-ext animals. One-way ANOVA revealed a significant main effect of group $\left(F_{(2,33)}=\right.$ $33.31 ; p<0.001)$. Post hoc test showed that the CPP-ext rats recovered significantly higher levels of freezing compared with saline-ext rats $(p<0.001)$ but were not significantly different 


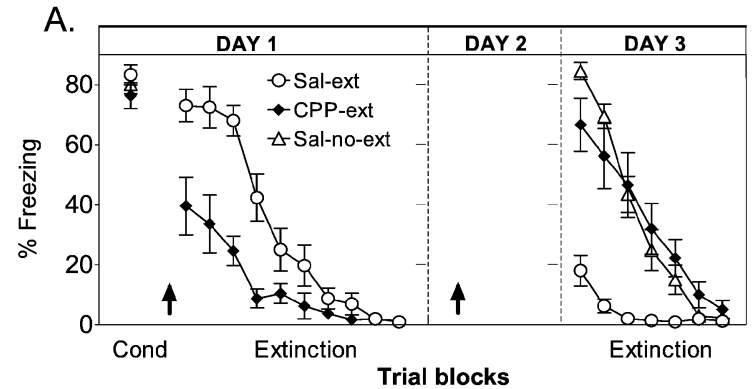

B.

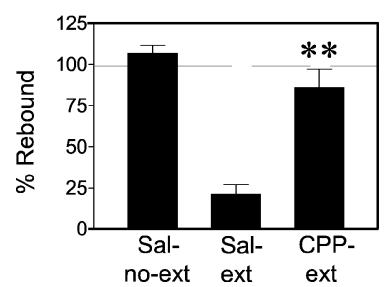

C.

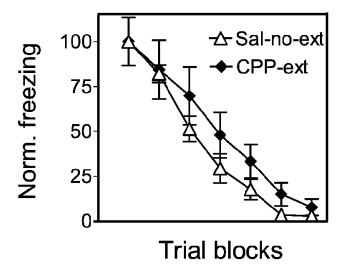

Figure 4. Experiment 4: CPP injected on the rest day prevents recall of extinction learned under CPP. $A$, Average percentage freezing to the tone for sal-no-ext $(n=12)$, CPP-ext $(n=12)$, and sal-ext $(n=12)$ groups. Rats were injected before the extinction session on day 1 and also on day 2. CPP-ext rats showed high levels of freezing on day 3 , indicating poor recall of extinction memory. $B$, Percentage rebound of freezing on day 3 . The CPP-ext rats were significantly higher than saline-ext rats $(* * p<$ $0.001)$ but were not significantly different from the no-extinction controls. $C$, Extinction of freezing on day 3 normalized to the first trial block. The rate of re-extinction was similar in both groups, suggesting no savings from extinction learned under CPP.

from the no-extinction controls $(p=0.17)$. Also, as in experiment 1 , CPP-ext rats showed no savings in their rate of reextinction on day 3 compared with the no-extinction controls (Fig. 4C). Thus, blocking of NMDA receptors on the rest day caused rats to be amnesic for extinction learned $48 \mathrm{hr}$ previously under CPP. This stands in contrast to experiment 2 in which $48 \mathrm{hr}$ retention of extinction learned under CPP was normal. The key difference between the two experiments was the availability of NMDA receptors at a time when no training was occurring, suggesting a role of NMDA receptors in post-learning consolidation processes.

\section{The effect of CPP on recall of extinction is unrelated to suppression of freezing during learning}

We have suggested that the high rebound observed in CPP-ext rats indicates amnesia for extinction training. However, another possibility is that high rebound is caused by impaired expression of freezing under CPP during extinction training. Reduced freezing during extinction could impair extinction learning and cause high rebound at test.

This is unlikely because the CPP-ext rats in experiment 2 showed both reduced freezing on day 1 and low rebound during testing on day 3. However, to formally test this possibility, CPPext rats in experiments 1,2 , and 4 were rank-ordered according to freezing levels at the outset of extinction training. Each CPP-ext group was then divided into two CPP subgroups: CPP-high freeze (those with the most initial freezing) and CPP-low freeze (those with the least initial freezing). Freezing in these two subgroups was then compared during extinction learning and at recall test, as shown in Figure 5. In each experiment, CPP-high freeze rats were indistinguishable from sal-ext rats on day 1 ,
A. Exp. 1

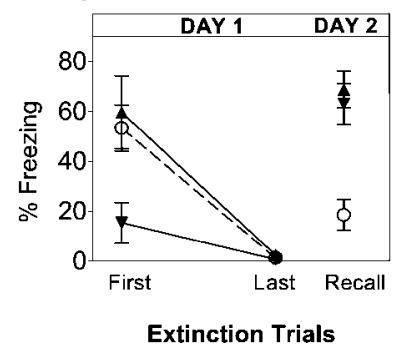

C. Exp. 4

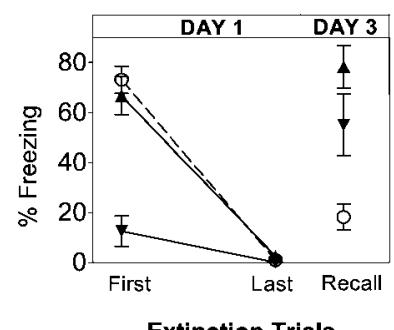

B. Exp. 2

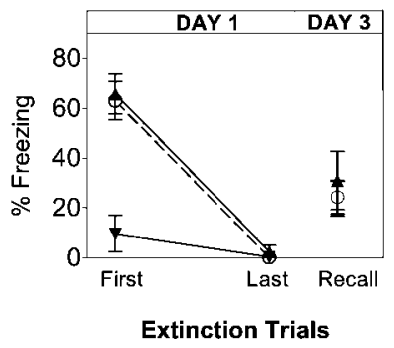

Extinction Trials
Figure 5. The effect of CPP on expression of freezing is unrelated to its effect on memory. $A$, For experiment 1 , the CPP-ext group was divided into two CPP subgroups: those showing the lowest freezing at the beginning of extinction on day $1(C P P$-low-frz.; $n=5)$ and those showing the highest freezing (CPP-high-frz.; $n=6)$. The average freezing for each CPP subgroup is compared with sal-ext rats for the first and last block of extinction training on day 1 and the recall test on day 2. Despite the pronounced difference in day 1 freezing, both subgroups showed equivalently high freezing when tested on day $2 . B$, In contrast, for experiment 2, CPP-high frz $(n=6)$ and CPP-low frz $(n=6)$ subgroups showed marked differences in freezing on day 1 but equivalently low freezing on day 3 that overlapped with the sal-ext group. $C$, In experiment 4, CPPhigh frz $(n=6)$ and CPP-low frz $(n=6)$ subgroups both rebounded to high levels on day 3 .

whereas CPP-low freeze rats hardly froze at all throughout extinction training. Nevertheless, the amount of freezing during the test was the same for both subgroups in all experiments. CPP subgroups showed equally high freezing at test in experiments 1 and 4 and equally low freezing at test in experiment 2. Student's $t$ tests confirmed that the CPP-ext subgroups did not differ significantly from each other at test (experiment $1, p=0.60$; experiment $2, p=0.56$; experiment $4, p=0.20$ ). Thus, the degree of rebound in CPP-ext rats was unrelated to the amount of freezing on day 1 but was instead determined by the learning-test interval and the availability of NMDA receptors on the rest day. We conclude that extinction learning was essentially normal in the presence of CPP, despite a reduction in average freezing levels. The fact that this reduction occurred in only half the rats injected with CPP suggests that $10 \mathrm{mg} / \mathrm{kg}$ may be a threshold dose for suppression of freezing but suprathreshold for its effect on extinction memory. Given that intra-amygdalar inf usions of APV completely blocked the expression of freezing (Lee and Kim, 1998; Lee et al., 2001), the systemic dose that we used may have blocked only a subset of amygdala NMDA receptors.

\section{DISCUSSION}

We have examined the effect of the NMDA antagonist CPP on the ability of rats to extinguish conditioned freezing responses within a session and recall extinction learning 24 or $48 \mathrm{hr}$ later. CPP given before extinction training did not prevent extinction of conditioned freezing or conditioned suppression throughout a 90 
min session, suggesting the existence of an NMDA-independent form of plasticity that permits short-term memory for extinction. When tested $24 \mathrm{hr}$ later, however, CPP rats were indistinguishable from no-extinction controls, suggesting that NMDA receptors are necessary for consolidation processes leading to longterm memory of extinction. Surprisingly, delaying testing until 48 hr after extinction training reversed the effect of CPP on recall of extinction, implying the existence a process that can consolidate extinction memory in a delayed manner. This process was NMDA dependent because a second CPP injection on the rest day prevented recall of extinction on day 3. Finally, a single CPP injection on a rest day $24 \mathrm{hr}$ before test did not impair recall of extinction, ruling out the possibility that CPP causes nonspecific increases in fear.

\section{NMDA receptors are involved in long-term but not short-term memory of extinction}

Prior studies did not assess the involvement of NMDA receptors in short-term extinction memory, either because too few extinction trials were administered per session (Falls et al., 1992; Cox and Westbrook, 1994; Baker and Azorlosa, 1996) or because NMDA antagonists completely blocked the expression of conditioned freezing (Lee and Kim, 1998). Preserved extinction learning under CPP cannot be attributed to rapid clearance of the drug before the end of the extinction session ( $2.5 \mathrm{hr}$ after injection) because the same dose of CPP blocks hippocampal LTP (Abraham and Mason, 1988) and hippocampal prime burst potentiation (Kentros et al., 1998) for at least $3 \mathrm{hr}$. We note, however, that CPP is not equally efficient in blocking all forms of NMDA receptors (Hrabetova and Sacktor, 1997). CPP has a higher affinity for the NR2A and NR2B subunits that subserve LTP than for the NR2C and NR2D subunits that subserve long-term depression (LTD). Thus, NMDA-dependent LTD may play a role in short-term extinction memory. It would be valuable to test the effects of APV on short-term extinction memory because this drug blocks both LTP and LTD.

Despite preserved short-term extinction memory, CPP injected at the time of training dramatically impaired long-term extinction memory. The high rebound of extinguished freezing in CPPtreated rats suggests that CPP caused amnesia for extinction training. This is consistent with an impairment of fear extinction when extinction training was done over many days in the presence of NMDA blockers (Falls et al., 1992; Cox and Westbrook, 1994; Baker and Azorlosa, 1996). Although our data are compatible with the idea that CPP induces amnesia for long-term extinction memory, alternative explanations must be discussed. (1) CPPtreated rats may have undergone state-dependent learning on day 1 (Overton, 1985; Cox and Westbrook, 1994), which would require CPP at test for recall of extinction memory. (2) CPP may have interfered with processing of the auditory CS (Webber et al., 1999), making it impossible for rats to form a new association between the tone and the absence of shock. (3) The reduced expression of freezing under CPP may have interfered with extinction learning. All of these explanations predict that recall of extinction in a drug-free test should be impaired, regardless of delay. In experiment 2, however, we observed normal recall of extinction $48 \mathrm{hr}$ after learning under CPP, suggesting normal extinction learning on day 1 in the presence of CPP. We also observed no correlation between the suppression of freezing by CPP and the degree of rebound at test. We therefore think that these alternative explanations are flawed and contend that there is an amnesic effect of CPP at the $24 \mathrm{hr}$ recall test.
Selective involvement of NMDA receptors at longer retention intervals compared with shorter retention intervals has been reported for acquisition of contextual fear conditioning (Kim et al., 1992; Malkani and Rosen, 2001), fear potentiated startle (Walker and Davis, 2000), inhibitory avoidance (Kim and McGaugh, 1992), and the water maze (Steele and Morris, 1999). However, in these studies the duration of short-term retention was much shorter than the 90 min that we observed. A closer parallel to our findings is the effect of CPP on the stability of hippocampal place cell firing patterns (Kentros et al., 1998). When CPP-injected rats were exposed to a novel environment, their hippocampal pyramidal cells adopted new positional firing patterns in a normal manner. Moreover, these newly formed firing patterns were stable for at least $90 \mathrm{~min}$. Twenty-four hours later, however, the new patterns in CPP-injected rats were replaced by yet another set of firing patterns, in contrast to the stability seen in saline-injected rats. Thus, together with the place cell results, our findings are consistent with a parallel organization of short-term and long-term memory, both starting during learning but having different time courses and molecular mechanisms (McGaugh, 2000). The coupling of short-term NMDAindependent mechanisms with long-term NMDA-dependent mechanisms may be a general scheme in memory formation, applicable to spatial learning, acquisition of fear conditioning, and now extinction learning.

\section{Delayed consolidation of extinction learning}

It is generally believed that a $24 \mathrm{hr}$ memory deficit indicates a permanent absence of memory, caused by blockage of NMDAdependent calcium entry and the subsequent molecular cascade of events leading to the formation of long-term memory (Kandel, 1997; Elgersma and Silva, 1999; Abel and Lattal, 2001). In fact, most previous studies of NMDA antagonists have interpreted 24 hr recall deficits in this way (Kim et al., 1992; Fanselow et al., 1994; Kentros et al., 1998; Shors and Mathew, 1998; Walker and Davis, 2000; Malkani and Rosen, 2001). How then is it possible to find apparently normal memory for extinction after doing no more than allowing an additional $24 \mathrm{hr}$ to pass between training and testing? Having ruled out state-dependent learning and similar explanations, we propose that a partial extinction memory is present in CPP animals at $24 \mathrm{hr}$ but is degraded in some way and cannot support expression of extinction. On the rest day in experiment 2 , a delayed consolidation process converts this partial memory into one that is fully accessible and stable.

Similar to ordinary consolidation, delayed consolidation appears to require NMDA receptors as suggested by experiment 4 , in which a single injection of CPP on the rest day prevented consolidation. One might wonder why sufficient consolidation on the rest day did not occur after CPP wore off. Given that the effects of CPP on hippocampal LTP have been shown to last from 8 to $20 \mathrm{hr}$ (Abraham and Mason, 1988), we speculate that the duration of drug-free processing after the injection was not sufficient to form stable extinction memory. Thus, it appears that extinction training must be followed by an extended and uninterrupted period during which NMDA channels are available. If sufficient time for NMDA-mediated consolidation is allowed (as in experiments 2 and 3 ), extinction is recalled at test, but if there is not enough time (experiments 1 and 4 ), extinction learning is not recalled. We therefore argue that NMDA-mediated processes can be delayed but cannot be bypassed for establishing long-term extinction memory.

To date, most studies have focused on the effects of NMDA 
antagonists during the acquisition phase of learning, although some reports of NMDA-dependent consolidation have appeared (Liang et al., 1994; Melan et al., 1997; Mello et al., 2000). A recent study by Tsien and colleagues (Shimizu et al., 2000) used a transgenic approach to show that NMDA receptors in the hippocampus participate in the consolidation of both contextual fear conditioning and spatial memory (Shimizu et al., 2000). Given the well known role of NMDA receptors as coincidence detectors, it was suggested that consolidation involves off-line synaptic strengthening of hippocampal-neocortical circuits required for stable long-term memory. According to this view, consolidation is a replay process that strengthens memory through NMDAdependent plasticity (Sutherland and McNaughton, 2000). We now suggest that NMDA-dependent plasticity may underlie relearning processes in which vicarious supplemental training can reinforce a damaged or partially formed extinction memory.

\section{Implications for models of memory formation}

In Figure 6 we summarize the relationship of our findings to traditional models of NMDA-mediated memory formation. The accepted model is usually depicted as a two-step process (Fig. $6 A$ ). A learning event causes activation of postsynaptic NMDA receptors, leading to an influx of calcium. Calcium has short-term effects such as increasing the number of AMPA channels or increasing conductance of AMPA channels leading to early plasticity. Calcium influx also has long-term effects via protein kinases and protein synthesis, which induce morphological changes that underlie late plasticity. Support for this two-stage model comes from studies of hippocampal LTP in which inhibitors of protein kinases and protein synthesis block late-phase LTP but not earlyphase LTP (Krug et al., 1984; Huang and Kandel, 1994; Nguyen et al., 1994). In addition to dependence on NMDA receptors, recent evidence suggests that long-term extinction memory requires protein synthesis (Berman and Dudai, 2001; but see Lattal and Abel, 2001).

In contrast to this simple two-stage model, the preserved shortterm memory observed during NMDA blockade suggests, in agreement with Kentros et al. (1998), that there must be a parallel, NMDA-independent early plasticity mechanism that can support short-term memory, at least for $2 \mathrm{hr}$ (Fig. 6B) (it is a separate question whether early and late plastic changes take place at the same synapses). This second model predicts both the preserved short-term memory and the impaired $24 \mathrm{hr}$ recall observed in experiment 1. Mere inclusion of NMDAindependent early plasticity is not consistent, however, with either the rescued memory observed after $48 \mathrm{hr}$ in experiment 2 or with the vulnerability of that memory to NMDA blockade on the rest day. Accordingly, we suggest that information stored by NMDA-independent early plasticity processes can be read and transferred to an NMDA-dependent form with stabilization that requires protein synthesis (Fig. $6 C$ ). Thus, prolonged activation of glutamatergic connections and consequent involvement of NMDA receptors after learning may constitute the proposed rehearsal or relearning processes.

Under ordinary circumstances, the formation of long-term memory may require NMDA receptors to be available at the time of learning. Alternatively, application of NMDA receptor blockers after learning may reveal a post-learning window of vulnerability. The preserved long-term extinction memory that we observed when CPP was given $24 \mathrm{hr}$ after training (experiment 3) suggests that such a window of vulnerability is over by $24 \mathrm{hr}$. However, recent studies have revealed the presence of several

\section{A. Accepted model}

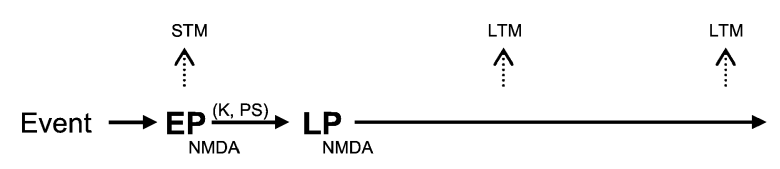

B. Model consistent with Exp. 1, but not Exp. 2

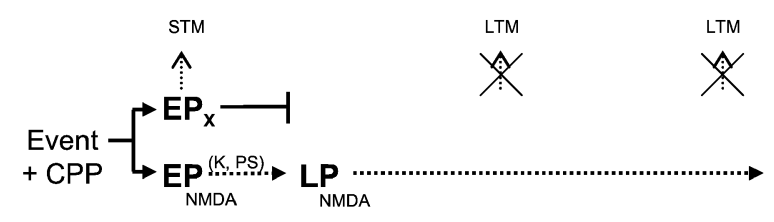

C. Model consistent with Exps. 1-4

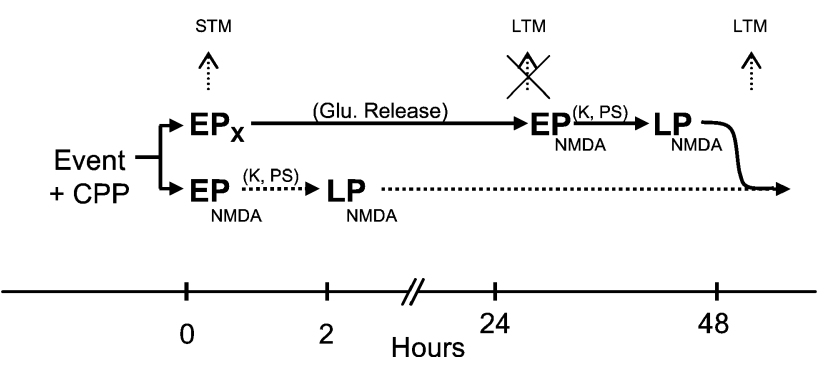

Figure 6. Models of NMDA-dependent memory formation. $A$, In the accepted model, an event is accompanied by the release of glutamateactivating NMDA receptors. The resulting influx of calcium leads to early plasticity $\left(E P_{N M D A}\right)$ supporting short-term memory $(S T M)$. Subsequent activation of kinases and protein synthesis $(K, P S)$ in the cell leads to NMDA-dependent late plasticity $\left(L P_{N M D A}\right)$ that supports long-term memory $(L T M) . B, C P P$ blocks the $\mathrm{EP}_{\mathrm{NMDA}}$ pathway (dotted line), but STM is still observed, suggesting the presence of an NMDA-independent early plasticity $\left(E P_{X}\right)$ that exists in parallel with the NMDA pathway. Consequently, testing at $24 \mathrm{hr}$ reveals no LTM. Although consistent with experiment 1 , this model is not consistent with experiment 2 , which showed preserved LTM at $48 \mathrm{hr}$. $C$, To account for the preserved LTM at $48 \mathrm{hr}$ (experiment 2), which was blocked by CPP injected on the rest day (experiment 4), we suggest that NMDA-independent early plasticity $\left(E P_{X}\right)$ is followed by prolonged activity in a glutamatergic circuit. On day 2, CPP has worn off, and NMDA receptors are again available for $\mathrm{EP}_{\mathrm{NMDA}}$ and $\mathrm{LP}_{\mathrm{NMDA}}$ processes that support long-term extinction memory from day 3 onward. Thus, under these circumstances, NMDA receptors can be activated after learning to consolidate extinction memory.

discrete post-training windows during which blocking protein kinases or protein synthesis prevents later recall (Freeman et al., 1995; Bourtchouladze et al., 1998). These windows can occur as late as $48 \mathrm{hr}$ after training (Chew et al., 1996), raising the interesting possibility that late waves of protein synthesis may be initiated by corresponding late waves of NMDA activity. If so, CPP given during extinction training may cause consolidation to "skip" one or more windows, effectively starting consolidation at a later point in time, but leaving the fundamental mechanisms unchanged.

\section{Possible sites involved in NMDA-mediated consolidation of extinction}

The effects of NMDA receptor blockade on extinction memory that we now report are very similar to the effects of lesions of the vmPFC (Quirk et al., 2000). Thus, short-term memory for extinction was preserved, but $24 \mathrm{hr}$ recall of extinction was deficient. NMDA-dependent LTP has been observed in vmPFC (Jay et al., 
1996), and the time course of our NMDA effects parallels the time course of extinction-induced plasticity in mPFC (Herry et al., 1999), consistent with vmPFC as a site of extinction learning. An additional possibility is the involvement of regions to which mPFC projects. For example, the vmPFC sends robust glutamatergic projections to the amygdala, especially its central nucleus (McDonald et al., 1996), which is the origin of amygdala efferents to brainstem sites that mediate freezing, suppression, and other conditioned fear behaviors (Kapp et al., 1979; LeDoux et al., 1988; Helmstetter, 1992; Campeau and Davis, 1995; Maren, 1999; Amorapanth et al., 2000). An amygdalar site of action agrees with the effects of intra-amygdala APV on extinction (Falls et al., 1992; Lee and Kim, 1998; Lee et al., 2001). Microinfusion of NMDA receptor antagonists into the vmPFC and other structures will be needed to determine the exact locus of NMDA-mediated processes in consolidation of extinction learning.

\section{REFERENCES}

Abel T, Lattal KM (2001) Molecular mechanisms of memory acquisition, consolidation and retrieval. Curr Opin Neurobiol 11:180-187.

Abraham WC, Mason SE (1988) Effects of the NMDA receptor/channel antagonist CPP and MK801 on hippocampal field potentials and longterm potentiation in anesthetized rats. Brain Res 462:40-46.

Amorapanth P, LeDoux JE, Nader K (2000) Different lateral amygdala outputs mediate reactions and actions elicited by a fear-arousing stimulus. Nat Neurosci 3:74-79.

Baker JD, Azorlosa JL (1996) The NMDA antagonist MK-801 blocks extinction of Pavlovian fear conditioning. Behav Neurosci 110:618-620.

Berman DE, Dudai Y (2001) Memory extinction, learning anew, and learning the new: dissociations in the molecular machinery of learning in cortex. Science 291:2417-2419.

Blanchard DC, Blanchard RJ (1972) Innate and conditioned fear reactions to threat in rats with amygdaloid lesions. J Comp Physiol Psychol $81: 281-290$

Bourtchouladze R, Abel T, Berman N, Gordon R, Lapidus K, Kandel ER (1998) Different training procedures recruit either one or two critical periods for contextual memory consolidation, each of which requires protein synthesis and PKA. Learn Mem 5:365-374.

Bouton ME (2000) A learning theory perspective on lapse, relapse, and the maintenance of behavior change. Health Psychol 19:57-63.

Bouton ME, Bolles RC (1980) Conditioned fear assessed by freezing and by the suppression of three different baselines. Anim Learn Behav 8:429-434.

Campeau S, Davis M (1995) Involvement of the central nucleus and basolateral complex of the amygdala in fear conditioning measured with fear potentiated startle in rats trained concurrently with auditory and visual conditioned stimuli. J Neurosci 15:2301-2311.

Chew SJ, Vicario DS, Nottebohm F (1996) Quantal duration of auditory memories. Science 274:1909-1914.

Cox J, Westbrook RF (1994) The NMDA receptor antagonist MK-801 blocks acquisition and extinction of conditioned hypoalgesic responses in the rat. Q J Exp Psychol B 47:187-210.

Elgersma Y, Silva AJ (1999) Molecular mechanisms of synaptic plasticity and memory. Curr Opin Neurobiol 9:209-213.

Estes WK, Skinner BF (1941) Some quantitative properties of anxiety. J Exp Psychol 29:390-400.

Falls WA, Miserendino MJD, Davis M (1992) Extinction of fearpotentiated startle: blockade by infusion of an NMDA antagonist into the amygdala. J Neurosci 12:854-863.

Fanselow MS, Kim JJ, Yipp J, De Oca B (1994) Differential effects of the $N$-methyl-D-aspartate antagonist DL-2-amino-5-phosphonovalerate on acquisition of fear of auditory and contextual cues. Behav Neurosci 108:235-240.

Fendt M (2001) Injections of the NMDA receptor antagonist aminophosphonopentanoic acid into the lateral nucleus of the amygdala block the expression of fear-potentiated startle and freezing. J Neurosci 21:4111-4115.

Fendt M, Fanselow MS (1999) The neuroanatomical and neurochemical basis of conditioned fear. Neurosci Biobehav Rev 23:743-760.

Freeman FM, Rose SP, Scholey AB (1995) Two time windows of anisomycin-induced amnesia for passive avoidance training in the dayold chick. Neurobiol Learn Mem 63:291-295.

Gewirtz JC, Davis M (2000) Using Pavlovian higher-order conditioning paradigms to investigate the neural substrates of emotional learning and memory. Learn Mem 7:257-266.

Gewirtz JC, Falls WA, Davis M (1997) Normal conditioned inhibition and extinction of freezing and fear-potentiated startle following elec- trolytic lesions of medial prefrontal cortex. Behav Neurosci 111:712-726

Helmstetter F (1992) The amygdala is essential for expression of conditioned hypoalgesia. Behav Neurosci 106:518-528.

Herry C, Vouimba RM, Garcia R (1999) Plasticity in the mediodorsal thalamo-prefrontal cortical transmission in behaving mice. J Neurophysiol 82:2827-2832.

Hrabetova S, Sacktor TC (1997) Long-term potentiation and long-term depression are induced through pharmacologically distinct NMDA receptors. Neurosci Lett 226:107-110.

Huang YY, Kandel ER (1994) Recruitment of long-lasting and protein kinase A-dependant long-term potentiation in the CA1 region of hippocampus requires repeated tetanization. Learn Mem 1:74-82.

Jay TM, Burette F, Laroche S (1996) Plasticity of the hippocampalprefrontal cortex synapses. J Physiol (Paris) 90:361-366.

Kandel ER (1997) Genes, synapses, and long-term memory. J Cell Physiol 173:124-125.

Kapp BS, Frysinger RC, Gallagher M, Haselton JR (1979) Amygdala central nucleus lesions: effects on heart rate conditioning in the rabbit. Physiol Behav 23:1109-1117.

Kentros C, Hargreaves E, Hawkins RD, Kandel ER, Shapiro M, Muller RU (1998) Abolition of long-term stability of new hippocampal place cell maps by NMDA receptor blockade. Science 280:2121-2126.

Killcross S, Robbins TW, Everitt BJ (1997) Different types of fearconditioned behavior mediated by separate nuclei within amygdala. Nature 388:377-380.

Kim JJ, DeCola JP, Landeira-Fernandez J, Fanselow MS (1991) $N$-methyl-D-aspartate receptor antagonist APV blocks acquisition but not expression of fear conditioning. Behav Neurosci 105:126-133.

Kim JJ, Fanselow MS, DeCola JP, Landeira-Fernandez J (1992) Selective impairment of long-term but not short-term conditional fear by the $N$-methyl-D-aspartate antagonist APV. Behav Neurosci 106:591-596.

Kim M, McGaugh JL (1992) Effects of intra-amygdala injections of NMDA receptor antagonists on acquisition and retention of inhibitory avoidance. Brain Res 585:35-48.

Krug M, Lossner B, Ott T (1984) Anisomycin blocks the late phase of long-term potentiation in the dentate gyrus of freely moving rats. Brain Res Bull 13:39-42.

Lattal KM, Abel T (2001) Different requirements for protein synthesis in acquisition and extinction of spatial preferences and context-evoked fear. J Neurosci 21:5773-5780.

LeDoux JE (2000) Emotion circuits in the brain. Annu Rev Neurosci 23:155-184.

LeDoux JE, Iwata J, Cicchetti P, Reis DJ (1988) Different projections of the central amygdaloid nucleus mediate autonomic and behavioral correlates of conditioned fear. J Neurosci 8:2517-2529.

Lee H, Kim JJ (1998) Amygdalar NMDA receptors are critical for new fear learning in previously fear-conditioned rats. J Neurosci 18:8444-8454.

Lee HJ, Choi JS, Brown TH, Kim JJ (2001) Amygdalar NMDA receptors are critical for the expression of multiple conditioned fear responses. J Neurosci 21:4116-4124.

Lehmann J, Schneider J, McPherson S, Murphy DE, Bernard P, Tsai C, Bennett DA, Pastor G, Steet DJ, Boehm C, Cheney DL, Liebman JM, Williams M, Wood PL (1987) CPP, a selective N-methyl-D-aspartate (NMDA)-type receptor antagonist: characterization in vitro and in vivo. J Pharmacol Exp Ther 240:737-746.

Liang KC, Hon W, Davis M (1994) Pre- and posttraining infusion of $N$-methyl-D-aspartate receptor antagonist into the amygdala impair memory in an inhibitory avoidance task. Behav Neurosci 108:241-253.

Malkani S, Rosen JB (2001) N-methyl-D-aspartate receptor antagonism blocks contextual fear conditioning and differentially regulates early growth response- 1 messenger RNA expression in the amygdala: implications for a functional amygdaloid circuit of fear. Neuroscience 102:853-861.

Maren S (1999) Neurotoxic basolateral lesions impair learning and memory but not performance of conditioned fear in rats. J Neurosci 19:8696-8703.

Maren S, Aharonov G, Stote DL, Fanelow MS (1996) N-methyl-Daspartate receptors in the basolateral amygdala are required for both acquisition and expression of fear in rats. Behav Neurosci 110:1365-1374.

McDonald AT, Mascagni F, Guo L (1996) Projections of the medial and lateral prefrontal cortices to the amygdala: a phaseolus vulgaris leucogglutinin study in the rat. Neuroscience 71:55-75.

McGaugh JL (2000) Memory - a century of consolidation. Science 287:248-251.

Melan C, Eichenlaud D, Ungerer A, Messier C, Destrade C (1997) Blockade of spontaneous posttraining performance improvement in mice by NMDA antagonists. Pharmacol Biochem Behav 56:589-593.

Mello E, Souza T, Vianna MR, Rodrigues C, Quevedo J, Moleta BA, Izquierdo I (2000) Involvement of the medial precentral prefrontal cortex in memory consolidation for inhibitory avoidance learning in rats. Pharmacol Biochem Behav 66:615-622. 
Morgan MA, Romanski LM, LeDoux JE (1993) Extinction of emotional learning: contribution of medial prefrontal cortex. Neurosci Lett 163:109-113.

Nguyen PV, Abel T, Kandel ER (1994) Requirement of a critical period of transcription for induction of a late phase of LTP. Science 265:1104-1107.

Overton DA (1985) Contextual stimulus effects of drugs and internal states. In: Context and Learning (Balsam PD, Tomie A, eds), pp 357-384. Hillsdale, NY: Erlbaum.

Pavlov IP (1927) Conditioned reflexes. London: Oxford UP.

Quirk GJ, Repa C, LeDoux JE (1995) Fear conditioning enhances shortlatency auditory responses of lateral amygdala neurons: parallel recordings in the freely behaving rat. Neuron 15:1029-1039.

Quirk GJ, Rosaly E, Romero RV, Santini E, Muller RU (1999) NMDA receptors are required for long-term but not short-term memory of extinction learning. Soc Neurosci Abstr 25:1620.

Quirk GJ, Russo GR, Barron JL, Lebrón K (2000) The role of medial prefrontal cortex in recovery of extinguished fear. J Neurosci 201:6225-6231.

Rescorla RA, Heth CD (1975) Reinstatement of fear to an extinguished conditioned stimulus. J Exp Psychol 1:88-96.

Shimizu E, Tang Y, Rampon C, Tsein JZ (2000) NMDA receptor- dependant synaptic reinforcement as a crucial process for memory consolidation. Science 290:1170-1174.

Shors TJ, Mathew PR (1998) NMDA receptor antagonism in the lateral/ basolateral but not central nucleus of the amygdala prevents the induction of facilitated learning in response to stress. Learn Mem 5:220-230.

Steele RJ, Morris RGM (1999) Delay-dependant impairment of a matching-to-place task with chronic and intrahippocampal infusions of NMDA-antagonist D-AP5. Hippocampus 9:118-136.

Sutherland GR, McNaughton B (2000) Memory trace reactivation in hippocampal and neocortical neuronal ensembles. Curr Opin Neurobiol 10:180-186.

Tang YP, Shimizu E, Dube GR, Rampon C, Kerchner GA, Zhuo M, Liu G, Tsien JZ (1999) Genetic enhancement of learning and memory in mice. Nature 401:63-69.

Walker LD, Davis M (2000) Involvement of NMDA receptors within the amygdala in short- versus long-term memory for fear conditioning as assessed with fear-potentiated startle. Behav Neurosci 114:1019-1033.

Webber TJ, Green EJ, Winters RW, Schneiderman N, McCabe PM (1999) Contribution of NMDA and non-NMDA receptors to synaptic transmission from brachium of the inferior colliculus to the media subdivision of the medial geniculate nucleus in the rabbit. Exp Brain Res 124:295-303. 